\title{
Effect of Olive Leaves Drying on the Content of Oleuropein
}

\author{
Ibraheem Afaneh1, Hiba Yateem², Fuad Al-Rimawi ${ }^{3}$ \\ ${ }^{1}$ Department of Food Technology, Faculty of Science and Technology, Al-Quds University, \\ Jerusalem, Palestine \\ ${ }^{2}$ Raed Cosmetics Co., Beit Sahour, Palestine \\ ${ }^{3}$ Chemistry Department, Faculty of Science and Technology, Al-Quds University, Jerusalem, \\ Palestine \\ Email: ${ }^{\text {falrimawi@science.alquds.edu }}$
}

Received 10 January 2015; accepted 9 February 2015; published 12 February 2015

Copyright (C) 2015 by authors and Scientific Research Publishing Inc.

This work is licensed under the Creative Commons Attribution International License (CC BY). http://creativecommons.org/licenses/by/4.0/

(c) (i) Open Access

\begin{abstract}
Oleuropein content in olive leaves dried at ambient temperature, and at elevated temperature $\left(50^{\circ} \mathrm{C}\right)$ from Palestinian olive trees collected from West Bank in the middle of November was determined by HPLC and compared to naturally dry olive leaves (collected dry from the tree). Results showed that higher concentration was obtained from olive leaves dried at room temperature $(10.0 \mathrm{mg}$ per gram of dry olive leaves), compared to those dried at $50^{\circ} \mathrm{C}(1.7 \mathrm{mg} / \mathrm{g})$, and those that collected dry from the tree $(2.5 \mathrm{mg} / \mathrm{g})$. Oleuropein content of dried olive leaves was compared with leaves that chopped and extracted fresh, and results show that fresh leaves showed the lowest oleuropein content $(<0.1 \mathrm{mg} / \mathrm{g})$ denoting that drying of leaves is required for high oleuropein recovery.
\end{abstract}

\section{Keywords}

Oleuropein, Drying, Olive Leaves, Extraction

\section{Introduction}

The olive tree, botanically-classified as Oleaeuropaea L., is one of the most important fruit trees in Mediterranean countries. Both the oil and the dried green-grayish colored leaves are used medicinally [1]. Oleuropein is the major phenolic compound of olive leaves and varies from $17 \%$ to $23 \%$ depending upon the harvesting time of the leaves [1]. The structure of oleuropein is shown in Figure 1. Hydrolysis of oleuropein yields elenolic acid

${ }^{*}$ Corresponding author. 




Figure 1. Structure of oleuropein.

glucoside and hydroxytyrosol. Many compounds isolated from Oleaeuropea fruits or leaves are thought to have been originated from Oleuropein via aglycon, by opening of olenolic acid ring with a final rearrangement into the secoiridoid compound such as hydroxytyrosol [2].

Various processing and extraction methods were investigated to evaluate stability and recovery of oleuropein from olive leaves [3]. Drying of olive leaves plays a significant role in the amount of oleuropein recovered from the leaves. Drying conditions include temperature, time, and method of drying (air-drying, microwave, freezedrying, etc). It is reported that increased levels of oleuropein were found in dried leaves than in fresh leaves probably due to the conversion of oleuropein glucoside into oleuropein by $\beta$-glucosidase present in fresh leaves [4].

Fresh olive leaf generally needs drying and milling before extraction. As a preservation method, drying is carried out to remove the water from the leaves to protect the leaves against spoilage and degradation of oleuropein by enzyme action. It also improves extraction efficiency or extractability. Air drying can be carried out at room temperature or elevated temperatures for different time periods [5]. Generally longer times are required for lower temperatures to achieve the same extent of dryness of leaves. Careful temperature control is needed during the drying since it may cause degradation of oleuropein. Malek \& Bradford [6] reported that air drying at an elevated temperature $\left(40^{\circ} \mathrm{C}\right)$ resulted in substantial losses of polyphenols possibly due to degradation of oleuropein and other polyphenols. Tayoub et al. [5] dried the fresh leaves in a ventilated oven for 72 hours at $40^{\circ} \mathrm{C}$ while Ansari et al. [7] dried the fresh olive leaves under ambient temperature.

Freeze drying is an alternative way to effectively avoid thermal degradation while removing the water from leaves. The leaves are immediately frozen in liquid nitrogen, and lyophilized before extraction [8]. The elimination of water through lyophilization generally does not affect the phenolic compounds excessively, and allows samples to be kept for longer periods [5]. However, it is not recommended as a sample drying method for olive leaves extraction as thawing of frozen olive leaf samples causes a sharp reduction in oleuropein levels due to breakage of cell membrane during thawing and consequently the release of active oleuropein-degrading enzymes [6]. Microwave drying is used for drying of olive leaves and results in higher concentrations of oleuropein [9]. Infrared drying was recently suggested as a good method for preserving olive leaves because it allows the retention of the green colour of fresh leaves. Infrared drying resulted in considerable moisture removal from the fresh leaves (more than $85 \%$ by weight) during a short drying period (varying from about 162 min at $42^{\circ} \mathrm{C}$ to $5 \mathrm{~min}$ at $70^{\circ} \mathrm{C}$ ). The total phenolic content of infrared dried olive leaves was greater compared to fresh ones [10].

In this respect, drying of olive leaves plays important role in oleuropein recovery from olive leaves. The aim of this work is therefore to study the effect of drying on the amount of oleuropein extracted from Palestinian olive leaves, by studying the effect temperature of drying $\left(25^{\circ} \mathrm{C}\right.$ and $\left.50^{\circ} \mathrm{C}\right)$, and comparing dried olive leaves with fresh olive leaves in terms of their oleuropein content.

\section{Materials and Methods}

\subsection{Sample Collection}

Olive leaf samples were obtained from trees localized in the sunshine area of grassland in Beit Sahour/West Bank/Palestine. The collection was directly from the trees in the middle of November 2012. In addition to those samples which were collected fresh (green) from the trees, other samples of olive leaves were obtained from a branch of a tree that is dry (brown olive leaves), i.e. this sample is obtained dry from the tree (naturally dried). 


\subsection{Sample Drying}

Fresh green leaves were dried using two procedures. In the first procedure, a portion of the fresh leaves were dried in ventilated oven at $50^{\circ} \mathrm{C}$, while in the second method, another portion of fresh leaves were dried at ambient temperature. The dried samples were then ground to obtain powder which was stored at room temperature in the dark until extraction. In the same way, dry (brown) olive leaves which are already dry were grinded to obtain powder, and were stored at room temperature in the dark until extraction. Green fresh olive leaves were chopped to obtain small pieces and stored at temperature between $2^{\circ} \mathrm{C}-8^{\circ} \mathrm{C}$ until extraction.

\subsection{Chemicals}

Oleuropein (40\%) which used as a standard was obtained from Chengdu Biopurity Phytochemicals Ltd. China. Chromatographic grade-double distilled water, HPLC grade acetonitrile (Merck), analytical grade acetic acid, ethanol, and ethyl acetate were obtained from Sigma-Aldrich company.

\subsection{Soxhlet Extraction of Olive Leaves Samples}

15 grams of olive leaves sample were placed in a Soxhlet thimble in a Soxhlet apparatus and extracted with 300 $\mathrm{ml}$ of solvent mixture for 4 hours at $60^{\circ} \mathrm{C}$. The solvent mixtures used for the extraction are: $80 \%$ ethanol/20\% water, $20 \%$ acetoniltrile/80\% water, and ethyl acetate $(100 \%)$. Then, the extracts were cooled to room temperature, and filtered through a Whatman No. 1 filter (Whatman, UK) to separate coarse particles from the solution. The filtered extracts were then evaporated in rotary evaporator at room temperature under vacuum for 2 hours. The concentrated extracts were stored in a refrigerator at $2^{\circ} \mathrm{C}$ to $8^{\circ} \mathrm{C}$ until analyzed for oleuropein content by HPLC.

\subsection{Preparation of the Mobile Phase and Standard Solutions}

The mobile phase was prepared by mixing $200 \mathrm{ml}$ of acetonitrile with $800 \mathrm{ml}$ of water for HPLC, and adding 1 $\mathrm{ml}$ of acetic acid.

Stock standard solution of oleuropein with a concentration of $1000 \mathrm{ppm}$ was prepared by dissolving $100 \mathrm{mg}$ of oleuropein in $100 \mathrm{~mL}$ of acetonitrile. Six solutions of oleuropein with concentrations: 3, 5, 100, 300, 500, and $800 \mathrm{ppm}$ were prepared from the stock standard solution by dilution using acetonitrile as diluent. These solutions were used for linearity and range study of the method. For recovery of oleuropein, three solutions of oleuropein spiked in blank (distilled water) at three concentrations (5.0, 100.0\%, and $1000.0 \mathrm{ppm}$ ) were prepared. These solutions used for recovery study were also used for precision study.

To determine LOD and LOQ of oleuropein using this method, solutions with low concentrations which is expected to produce a response of 3 - 20 times baseline noise were prepared. LOD is selected as the concentration of oleuropein that gives a $\mathrm{S} / \mathrm{N}$ ratio of $3-10$, while LOQ is selected as the concentration that gives a $\mathrm{S} / \mathrm{N}$ ratio of $10-20$.

\subsection{Determination of Oleuropein in Olive Leaf Extracts by HPLC}

HPLC system (Merck Hitachi Lachrome Elite HPLC System, Japan) with an L-2130 pump, an L-2200 auto sampler, L-2300 column oven, and L-2490 UV detector was employed. The Ezochrom Elite software was employed.

For determination of oleuropein from olive leaf extracts, reversed phase HPLC method was used with silcabased $\mathrm{C}_{18}$ bonded phase column $\left(\mathrm{C}_{18}, 250 \mathrm{~mm} \times 4.6 \mathrm{~mm} \mathrm{ID}, 5 \mu \mathrm{m}\right)$ with mobile phase consisting of a mixture of water and acetonitrile (80/20 volume ratio) containing $1 \%$ acetic acid at a flow rate of $1.0 \mathrm{~mL} / \mathrm{min}$. UV detector at $240 \mathrm{~nm}$ was used for oleuropein determination. The injection volume used is $20.0 \mu \mathrm{l}$ for both standard and sample solutions. Identification of oleuropein in olive leaves extracts was based on retention times in comparison with standard of oleuropein. The quantitation was carried out using external standard method. The concentration of oleuropein in the extracts was calculated using peak area and the calibration curves obtained from oleuropein standard solution. The amount of oleuropein was expressed as milligram per gram of olive leaf powder. Figure 2 shows chromatograms for oleuropein standard, sample of olive leaves, and a negative control of oleuropein. 




(a)

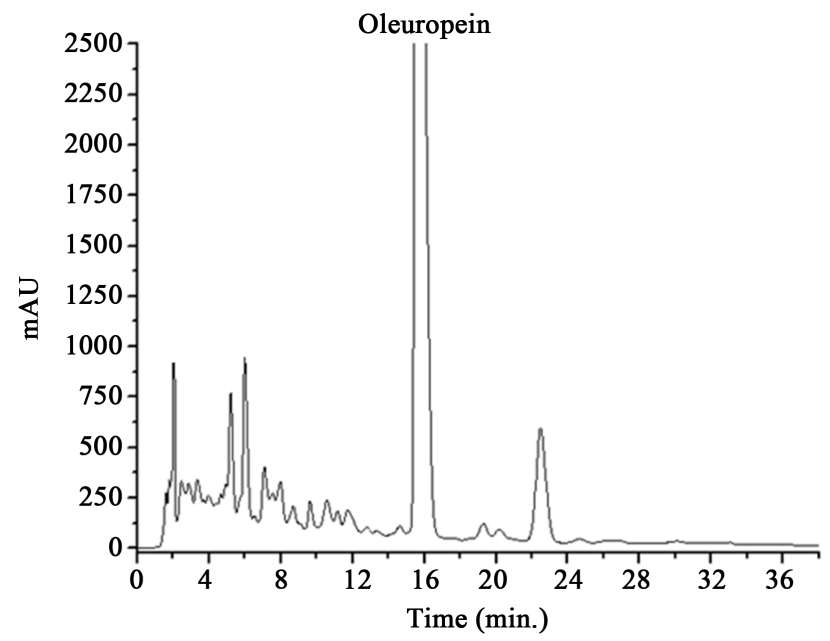

(b)

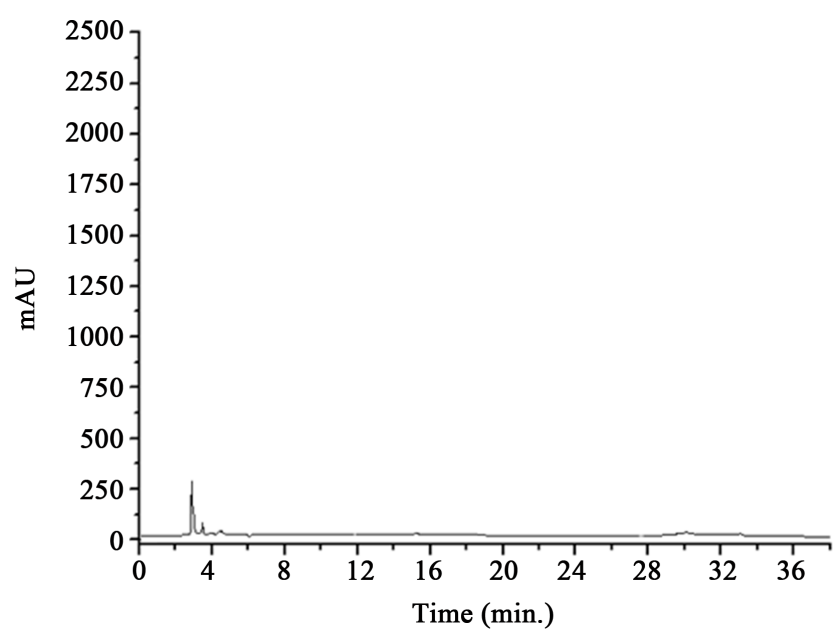

(c)

Figure 2. Chromatograms of oleuropein analyzed. (a) Standard of oleuropein; (b) Sample of olive leaves; (c) A negative control. Note: The other peaks which appears in the chromatogram of sample are for other compounds present in the olive leave. 


\subsection{Statistical Analysis}

Three samples of olive leaves extract of each treatment were independently analyzed in each sampling, and all of the determinations were carried out in triplicate. The results are expressed as means \pm standard deviations. All statistical analyses were carried out using SAS (SAS Institute Inc., Cary, USA, Release 8.02, 2001). Comparisons of means with respect to the influence of solvent type and drying condition were carried out using the General Linear Model (GLM procedure), treating main factors (type of solvent, drying condition) separately using one-way analysis of variance (ANOVA). The Bonferroni procedure was employed with multiple t-tests in order to maintain an experiment-wise of $5 \%$.

\section{Results \& Discussions}

\subsection{Extraction of Oleuropein}

Olive leaves samples were extracted with different solvents (ethyl acetate, $80 \%$ ethanol/20\% water, and 20\% acetonitrile/ $80 \%$ water) using soxhlet extraction. As it is shown in Table 1 the amount of oleuropein extracted using $20 \%$ acetonitrile $/ 80 \%$ water is $19.0 \mathrm{mg}$ per gram of olive leaves, which is significantly larger than the amount of oleuropein in olive leaves extracted with $80 \%$ ethanol/20\% water (15.6 mg per gram). Using ethyl acetate, very low amount of oleuropein was extracted $(0.19 \mathrm{mg} / \mathrm{g})$ which is only $1 \%$ of that oleuropein in olive leaves extracted with $20 \%$ acetonitrile/ $80 \%$ water. Statistically, there is a significant difference in the amounts of oleuropein extracted with the three solvents which is indicated by small letters (a, b, c) in Table 1 . This can be attributed to the polarity of the solvent used to extract oleuropein; large amounts of oleuropein are extracted using polar solvents such as $80 \%$ ethanol $/ 20 \%$ water or $20 \%$ acetonutrile/ $80 \%$ water, compared to low polar solvents such as ethyl acetate. This is expected as oleuropein has polar hydroxyl groups and so need polar solvent for extraction.

\subsection{Method Validation}

This method is validated according to the requirements for new methods, which include linearity and range, accuracy, precision, selectivity, limit of detection (LOD), and limit of quntitation (LOQ). The current method demonstrates good linearity over the range of $3-1000 \mathrm{ppm}$ of oleuropein with $\mathrm{r}^{2}$ greater than 0.999 . The recovery of oleuropein in olive leaves ranges from $97.7 \%$ to $101.1 \%$. The method is selective where oleuropein is good separated from other components with good resolution. The method is also precise where the RSD of the peak areas of replicate injections of oleuropein standard solution is less than 1\%. Low LOD and LOQ of oleuropein (3 and 5 ppm respectively) using this method enable the detection and quantitation of oleuropein at low concentration.

\subsection{Effect of Drying Temperature on Oleuropein Content}

Drying of olive leaves is essential to prevent microbial fermentation and subsequent degradation of phytochemicals and metabolites [4]. To study the effect of drying on the oleuropein content of olive leaves, fresh green leaves were dried at ambient temperature $\left(25^{\circ} \mathrm{C}\right)$, and elevated temperature $\left(50^{\circ} \mathrm{C}\right)$, and then milled to powder by an electrical mill and kept at ambient temperature in a dark place till analysis. Protection from direct sunlight is essential to minimize chemical reactions induced by ultraviolet rays. Olive leaves powder were extracted with a solvent mixture in the ratio of 1:20 (powder/solvent). For the chopped fresh olive leaves, first water content was determined by drying the sample at $40^{\circ} \mathrm{C}$ until constant weight is obtained. Then, 24 grams of chopped fresh leaves was used for extraction (which is equivalent to 15 gram of dry powder). Acetonitrile/water (80:20) was used as a solvent mixture for soxhlet extraction of all samples as it gave the highest oleuropein amount.

Results showed that the highest amount of oleuropein is obtained from olive leaves dried at ambient temperature (10.0 mg oleuropein per gram of dried leaf powder), see Table 2. Simple drying of fresh leaves at ambient

Table 1. Oleuropein content in olive leaves extracted by using soxhlet with different solvent mixtures.

\begin{tabular}{cc}
\hline Solvent Mixtures & Oleuropein Content (mg/g) \\
\hline Ethyl acetate & $0.19 \pm 0.01 \mathrm{c}$ \\
$80 \%$ ethanol/20\% water & $15.6 \pm 0.16 \mathrm{~b}$ \\
$20 \%$ acetonitrile/80\% water & $19.0 \pm 0.21 \mathrm{a}$ \\
\hline
\end{tabular}

Different small letters indicate significant differences within the column (extraction solvent). 
Table 2. Amounts of oleuropein found in olive leaves dried at ambient temperature and at $50^{\circ} \mathrm{C}$, and for natural dried olive leaves, and fresh olive leaves.

\begin{tabular}{cc}
\hline Drying Conditions & Oleuropein Content (mg/g) \\
\hline Ambient temperature $\left(25^{\circ} \mathrm{C}\right)$ & $10.0 \pm 0.26 \mathrm{a}$ \\
$50^{\circ} \mathrm{C}$ & $1.7 \pm 0.13 \mathrm{C}$ \\
Natural (brown) dried olive leaves & $2.5 \pm 0.21 \mathrm{~b}$ \\
Fresh green olive leaves & $0.0 \mathrm{~d}$ \\
\hline
\end{tabular}

Different small letters indicate significant differences within the column (drying conditions).

temperature protected oleuropein while drying at elevated temperature results in rapid degradation of oleuropein ( $1.7 \mathrm{mg} / \mathrm{g}$, which is only $17 \%$ of oleuropein recovered from olive leaves dried at $25^{\circ} \mathrm{C}$ ). Oleuropein content in natural dried olive leaves (dried naturally by the sun and air) was $2.5 \mathrm{mg} / \mathrm{g}$ which is lower than olive leaves dried at ambient temperature but higher than those dried at $50^{\circ} \mathrm{C}$. Browning of leaves occurs when oleuropein is oxidized to highly reactive quinines which then polymerized (browning is an interactions between diphenol oxidase activity and oleuropein content). Oleuropein content of fresh green olive leaves was very low (lower than $0.1 \mathrm{mg} / \mathrm{g}$ ), because the surface area was too low to facilitate the penetration of solvents into cells, so that oleuropein stayed protected in leaves cell. Scientific literature does not contain any reports that deal with green olive leaves and its content ofoleuropein. These results showed that drying of olive leaves at ambient temperature is the best method for high oleuropein recovery, which is in accordance of the results of Nasir et al., 2008.

\section{Conclusion}

Drying of olive leaves before extraction is required for high oleuropein content, as it prevents microbial fermentation and subsequent degradation. Drying of fresh olive leaves at ambient temperature is the best method because it preserves oleuropein from degradation compared to drying at elevated temperatures. Green olive leaves dried at ambient temperature gave higher amounts of oleuropein compared to olive leaves which are obtained dry from the tree. It is not recommended to extract oleuropein from fresh olive leaves as it gives low oleuropein content.

\section{References}

[1] Le Toutour, B. and Guedon, D. (1992) Antioxidative Activities of Oleaeuropaea Leaves and Related Phenolic Compounds. Phytochemistry, 31, 1173-1178. http://dx.doi.org/10.1016/0031-9422(92)80255-D

[2] Syed Haris, O. (2010) Oleuropein in Olive and Its Phamacological Effects. Scientia Pharmaceutica, 78, 133-154. http://dx.doi.org/10.3797/scipharm.0912-18

[3] Sawalha, S., Arraez-Roman, D., Sergura-Carretero, A. and Fernandez-Gtierrez, A. (2009) Characterization of Phenolic Compounds in Diatomaceous Earth Used in the Filtration Process of Olive Oil by HPLC-ES-TOF (MS). Agro Food Industry Hi-Tech, 20, 46-50.

[4] Silva, S., Gomes, L., Leitao, F., Coelho, A.V. and Vilas Boas, L. (2006) Phenolic Compounds and Antioxidant Activity of Oleaeuropaea L. Fruits and Leaves. Food Science and Technology International, 12, 385-396. http://dx.doi.org/10.1177/1082013206070166

[5] Tayoub, G., Sulaiman, H., Hassan, A.H. and Alorfi, M. (2012) Determination of Oleuropein in Leaves and Fruits of Some Syrian Varieties. 2, 428-433.

[6] Malik, N.S.A. and Bradford, J.M. (2008) Recovery and Stability of Oleuropein and Other Phenolic Compounds during Extraction and Processing of Olive (Oleaeuropea) Leaves. Journal of Food, Agriculture and Environment, 6, 8-13.

[7] Ansari, M., Kazemipour, M. and Fathi, S. (2011) Development of a Simple Green Extraction Procedure and HPLC Method for Determination of Oleuropein in Olive Leaf Extract Applied to a Multi-Source Comparative Study. Journal of the Iranian Chemical Society, 8, 38-47.

[8] Briante, R., la Cara, F., Frebbraio, F., Patumi, M. and Nucci, R. (2002) Biotransformation on Olea europea Leaf Extracts. Journal of Biotechnology, 93, 109-119. http://dx.doi.org/10.1016/S0168-1656(01)00387-X

[9] Bouaziz, M., Hammami, H., Bouallagui, Z., Jemai, H. and Sayadi, S. (2008) Production of Antioxidants from Olive Processing By-Products. Electronic Journal of Environmental, Agricultural and Food Chemistry, 7, 3231-3236. 
[10] Boudhrioua, N., Bahloul, N., Ben Slimen, I. and Kechaou, N. (2009) Comparison on the Total Phenol Contents and the Color of Fresh and Infrared Dried Olive Leaves. Industrial Crops and Products, 29, 412-419.

http://dx.doi.org/10.1016/j.indcrop.2008.08.001 
Scientific Research Publishing (SCIRP) is one of the largest Open Access journal publishers. It is currently publishing more than 200 open access, online, peer-reviewed journals covering a wide range of academic disciplines. SCIRP serves the worldwide academic communities and contributes to the progress and application of science with its publication.

Other selected journals from SCIRP are listed as below. Submit your manuscript to us via either submit@scirp.org or Online Submission Portal.

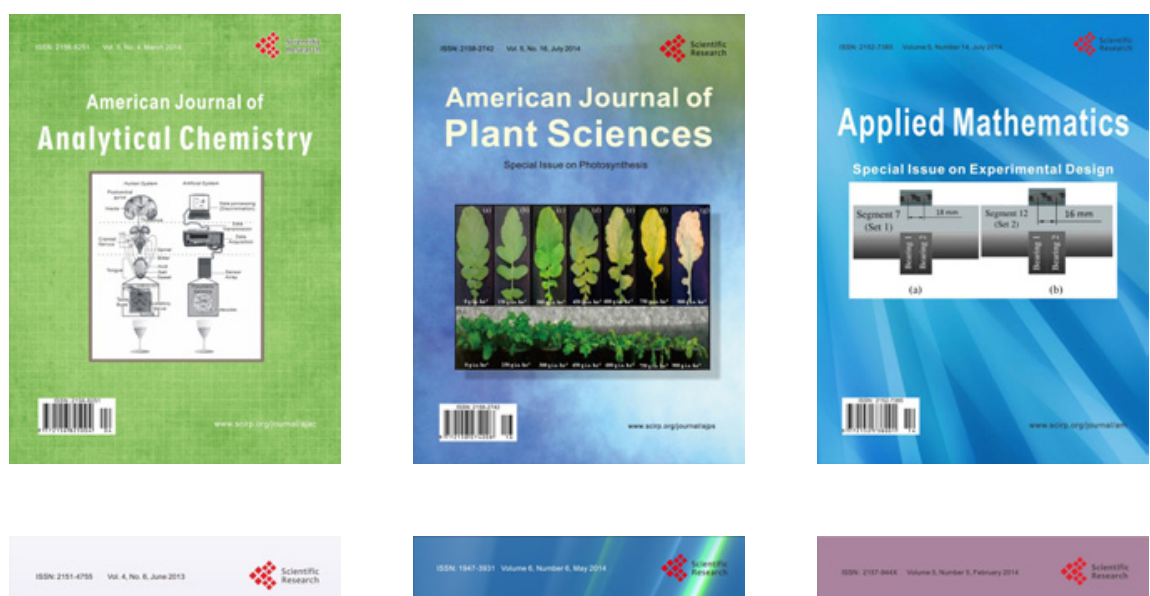

Creative Education
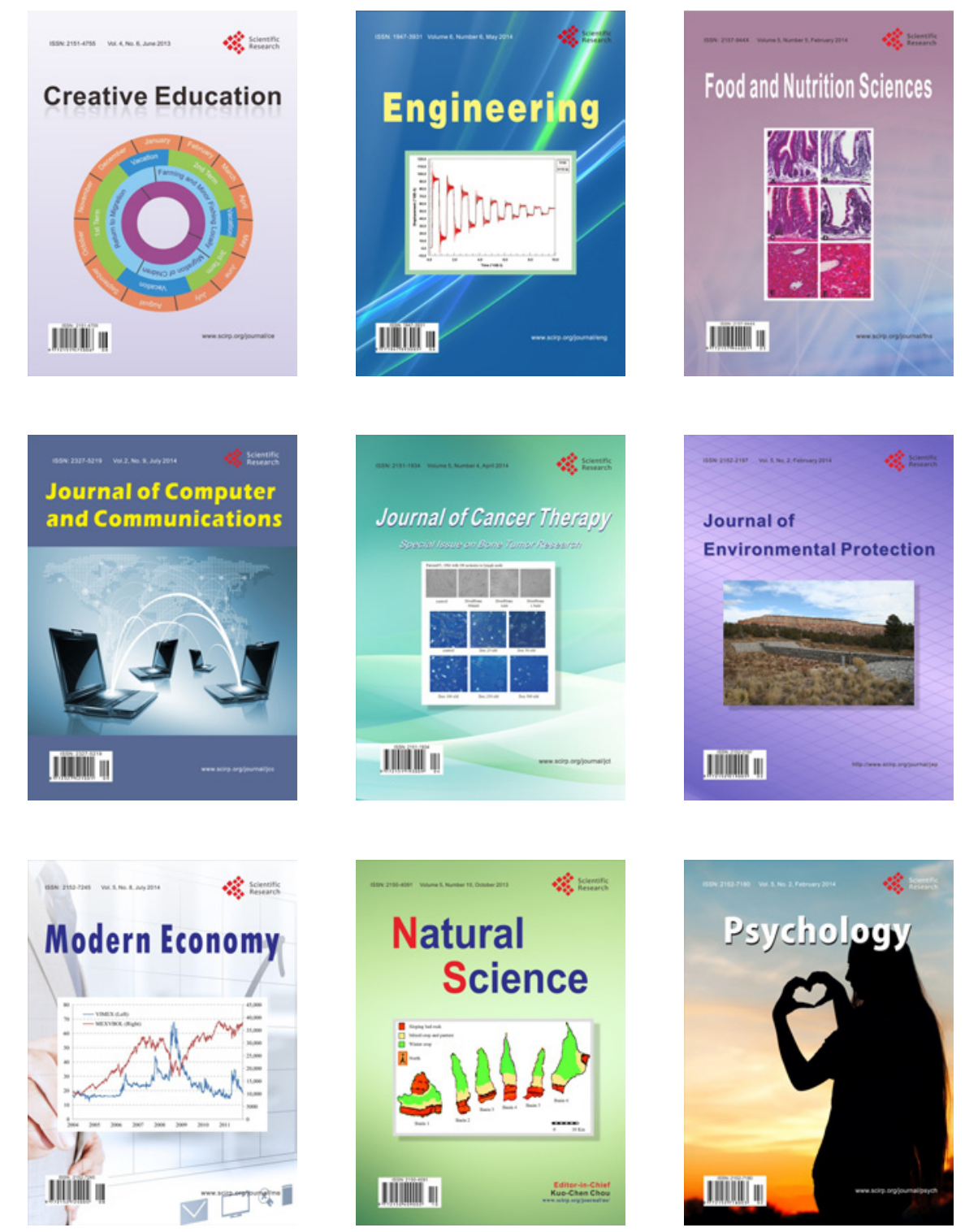